\title{
Variations in Flight Patterns of European Corn Borer (Lepidoptera: Pyralidae) in New York ${ }^{1}$
}

\author{
C. J. ECKENRODE, P. S. ROBBINS, AND J. T. ANDALORO² \\ Department of Entomology, New York State Agricultural Experiment Station, Geneva, New York 14456 \\ Environ. Entomol. 12: 393-396 (1983)

\begin{abstract}
Seasonal flights of Ostrinia nubilalis (Hübner) were monitored in 1981, using blacklight traps in 28 locations in central and westem New York state. Calendar date of peak catch and heat unit accumulations indicated the presence of both univoltine and bivoltine biotypes, although before this study, only the latter was assumed to be present in these regions. Both biotypes were evident at 16 of the 28 trapping sites. Trap catches during the last 5 years of a 15-year study (1967-1981), at a fixed location near Geneva, N.Y., indicated the recurrence of a univoltine population that had last been noted in this region before 1964. Losses due to larval contamination of processed snap beans are reported for 1979 and 1980. Growers of susceptible crops must be aware of local flights and the potential for shifts in peak moth emergence before insecticides are applied.
\end{abstract}

Variable voltinism became evident in European corn borer (ECB), Ostrinia nubilalis (Hübner), populations in the United States shortly after the pest was introduced (Caffrey and Worthley 1927). Two generations occurred cacl year in the area of Boston, Mass., whereas only one occurred in infested regions of New York state. Much later, Showers et al. (1975) reported that three ecolypes (based on diapause induction) existed in North America: a northern type (single generation per year), a central type (two generations per year), and a southern type (three or four generations per year). The singlegeneration (univoltine) biotype was believed to be dominant in central and western (upstate) New York until McEwen et al. (1968) reported that a two-generation (bivoltine) type was predominating at that time (1964 1967). It is assumed that the shift was fairly recent, although annual NYSAES reports (unpublished data) indicate that the bivoltine biotype had been present in upstate New York in detectable numbers since ca. 1940.

Field and sweet com have always been important hosts of this pest although large plantings of other potential host crops are grown each year in this region. However, in 1.979 and 1980 , complaints from growers and processors in New York indicated that the ECB had contaminated snap beans as it has done sporadically in other regions (Cress and Wells 1971, Dively and McCully 1979, Linduska and Dively 1981). Effective management of the pest depends upon prediction and monitoring of flights, followed by properly timed applications of insecticides on plantings which have reached a susceptible stage of development. For example, sprays are justified on snap beans shortly before bloom until 7 to 10 days before harvest, assuming that oviposition pressure is high enough to cause a contamination problem (Dively and McCully 1979). Because changes in behavior can occur due to invasion by new strains (Chiang 1972) or shifting weather patterns (Chiang et al. 1961), growers must be aware of current ECB flights in their respective areas to time insecticide applications with accuracy.
Temperautre summations have been correlated with ECB flights (primarily the bivoltine biotype) with some consistency (Apple 1952, McEwen et al. 1968, Clement et al. 1981). As predictive tools, heat units (day-degrees, thermal units, etc.) may have limited interregional use, because ECB populations can vary in their response to temperature, and the methods by which heat units are computed have not been standardized. However, within a region, temperature accumulations can be very useful if a suffficient data base is available for the determination of thermal requirements and proper care is taken in collecting temperature and computing the summations. In addition to predictive purposes, heat units may be used to identify various biotypes if their responses to temperature differ (McLeod 1976).

In this study, we document recent losses of snap beans for processing due to larval contamination by ECB. These losses precipitated an intensive survey of ECB flights in 1981 using the blacklight trap, an effective tool in monitoring ECB populations (Showers et al. 1974). In addition, flight trends during three consecutive 5-year periods from one location are discussed. Finally, temperature accumulations $\left({ }^{\circ} \mathrm{C}\right)$ are correlated with the various flight patterns to aid in separating biotypes and to assist growers in proper timing of insecticide applications.

\section{Materials and Methods}

\section{ECB Contamination of Snap Beans, 1979-1981}

Locations of ECB infestations and losses to snap bean growers were documented, using information obtained from snap bean processors based in New York during 1979 to 1981. An infestation is defined as a field (or portion of a field) that was rejected for processing because of unacceptable levels of EBC larvae in the harvested pods. The criterion for rejection of harvested bean pods has not been totally standardized, but even extremely low levels of ECB cannot be tolerated by processors.

\section{Survey of ECB Flights, 1981}

In response to concerns by snap bean processors regarding flight patterns, ECB moths were monitored in 
upstate New York in 28 locations, using blacklight traps (Ellisco, Inc., Philadelphia, Pa.). Sites were selected on the basis of close proximity to commercial plantings of snap beans or sweet corn. Captured moths were identified and counted two or three times per week, weather permitting. Because collection dates at the various trap sites were not synchronized, data were standardized by converting weekly totals to percentage of total catch. Biotypes were determined by the occurrence of significant flights ( $>5 \%$ of total season's catch) at particular selected day-degree (DD) accumulations. DD accumulations were computed from maximum-minimum daily temperatures above a base of $10^{\circ} \mathrm{C}$, using the methods (cases 1 and 2) reported by Baskerville and Emin (1969). Temperatures for each collection site were obtained from the nearest thermograph or weather station (up to $32 \mathrm{~km}$ distant) beginning 1 March.

Termination of diapause as supportive evidence for variable voltinism was determined by using overwintering larvae in 1982. Over 100 individuals were collected from com stalks in commercial fields located near light traps near Paris and Eden, N.Y. Larvae were placed on wheat germ diet in the laboratory with a photophase of $16 \mathrm{~h}$ and temperatures ranging from 25 to $30^{\circ} \mathrm{C}$. $\mathrm{Pu}$ pation was noted for each individual and $\mathrm{DD}$ accumulations were computed for $50 \%$ pupation.

\section{Flights at Geneva, N.Y., 1967-1981}

A blacklight trap has been operating at the Robbins Vegetable Research Farm near Geneva, N.Y., since 1964. McEwen et al. (1968) discussed moth catches at this site from 1964 to 1967, and the remaining catches (through 1981) are reported here. Collection intervals have varied from daily to twice weekly during this period. Data were standardized to weekly totals expressed in mean percent total catch for direct comparison with catches at other locations. Maximum and minimum daily temperatures were recorded from the Vegetable Crops Farm located ca. $2 \mathrm{~km}$ east of the light trap.

Flight records and DD accumulations from 1967 to $198 \mathrm{I}$ were averaged into three 5-year periods to clarify multiseasonal trends which may be occurring.

\section{Results and Discussion \\ ECB Contamination of Snap Beans, 1979-1981}

In 1979, four fields (or portions of fields) of varying sizes were bypassed for processing because of unacceptable larval contamination in the mature pods. Two fields were located near Paris, N.Y., and the other two fields were located $\mathrm{N}$ and $\mathrm{E}$ of Geneva near Lake Ontario. At that time, the existence of typical bivoltine strains in both areas was assumed, although ECB flights were not being monitored.

Figure 1 shows 21 sites of ECB infestation from a survey of snap bean processors in 1980 and indicates a marked increase in infestations when compared with those reported for 1979. In 1980, ca. 1,088 metric tons of harvested product were not accepted for processing because of unacceptable larval contamination, and a number of fields were not harvested. The loss of harvested

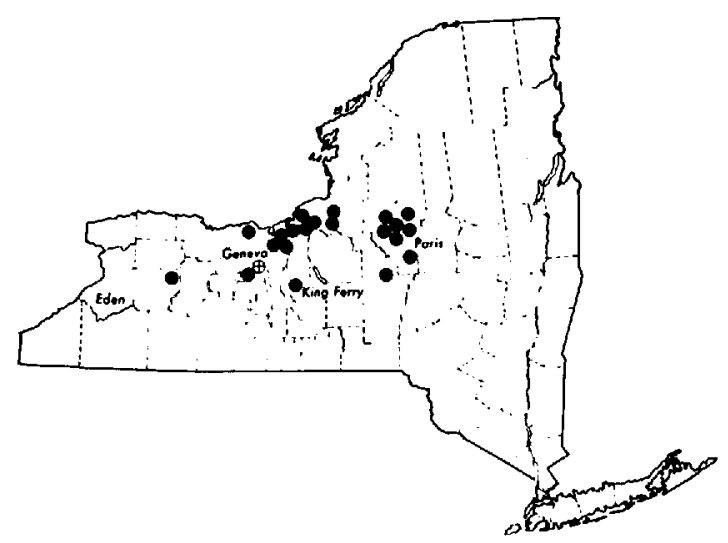

FIG. 1.-Sites of ECB infestation in snap beans for processing in upstate New York, 1980.

product was $>\$ 200,000$. Planting dates of contaminated fields ranged from 9 June to $3 \mathrm{July}$, and harvest dates ranged from 9 August to 4 September. Oviposition in these fields probably occurred during mid-July to late August. No losses were reported in 1981.

\section{Survey of ECB Flights, 1981}

Flight patterns varied considerably throughout upstate New York in 1981 (Fig. 2 and 3). Flights were classified into three types, based on the number and magnitude of peak moth catches compared with DD accumulations: bivoltine, univoltine, and a mixture. A representative of each one of these types is presented in Fig. 2. A typical bivoltine flight occurred near Eden, peaking on 20 June (395 DD) and 8-15 August (973 to 1079 DD) (Fig. 2A). In contrast to the bivoltine flight, a univoltine biotype occurred at several locations (Fig. 2B and 3). A typical single-generation catch was recorded near Paris, which peaked on 11 July (686 DD). This DD accumulation is considerably greater than the sum which occurs during the spring flight of the bivoltine strain and is less than expected for the second peak of bivoltine moths which fly in August.

In the laboratory, $50 \%$ pupation of overwintering larvae collected near Eden (a suspected bivoltine area) occurred at $170 \mathrm{DD}$ (ca. 9 days) earlier than the individuals collected near Paris where single flights had occurred previously. The DD sums for $50 \%$ pupation of the two populations were 395 and 565 for Eden and Paris, respectively. McLeod (1976) reported that individuals originating from areas in Ontario with single generations took longer to pupate than the individuals from bivoltine populations. He indicated that diapause termination was the main distinguishing feature between the geographical populations.

Figure $2 \mathrm{C}$ presents a third type of flight pattern where three distinct peaks were evident near King Ferry. Apparently, both uni- and bivoltine flights occurred in much of the state in 1981 (Fig. 3) as they have near Simcoe, Ontario (McLeod 1976). The first and third peaks (bivoltine) at King Ferry were similar in calendar date to 

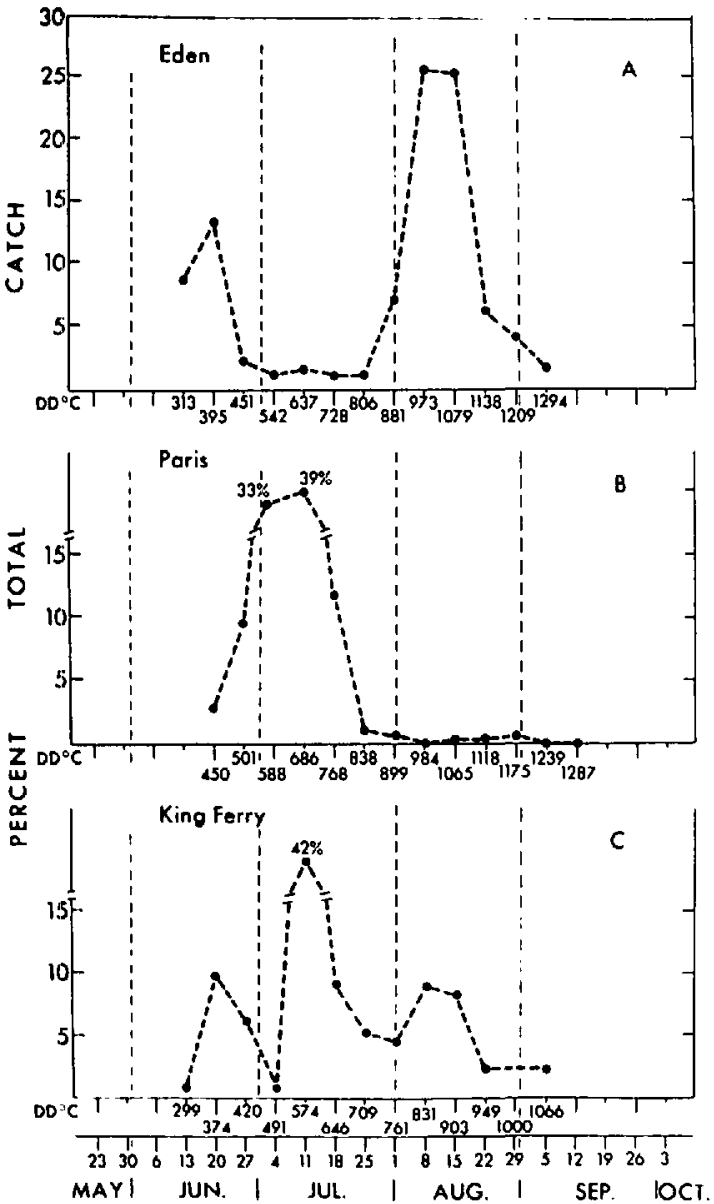

FIG. 2.-ECB trap catches at three locations in New York in 1981 showing bivoltine, univoltine and mixed flight patterns. The three locations also are shown in Fig. 1 and 3.

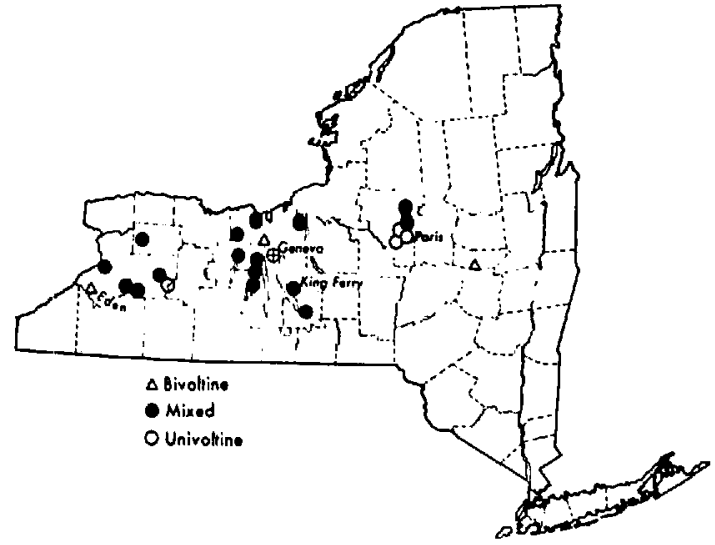

FIG. 3.-Bivoltine and univoltine biotypes based on blacklight trap catches from 28 locations in upstate New York in 1981.

the first and second peaks of a bivoltine pattern, but the DD accumulations for the third peak differed when com- pared with the Eden flights. A difference of $112 \mathrm{DD}$ occurred when the peak of the July flight at King Ferry (univoltine) was compared with the peak of the single flight near Paris (Fig. 2). These discrepancies probably occurred because of the considerable distance $(32 \mathrm{~km})$ between the light trap at King Ferry and the nearest weather station. The average DD sums for flights in all locations where the bivoltine type was present were 383 $(\mathrm{SD}=72)$ and $1,081(\mathrm{SD}=136)$ for the first and second peaks, respectively. In contrast, univoltine flights peaked at an average sum of $679(S D=90)$.

This apparent mixture of uni- and bivoltine strains was evident in 16 of the 28 locations (Fig. 3) and represents an important addition to the understanding of flight patterns occurring at the present time in this state. Shifts in voltinism are not uncommon, but frequently result from displacement of univoltine types by multiple generations (Wressell 1953, McEwen et al. 1968, McLeod et al. 1979). In many regions of upstate New York either a shift from bivoltine to univoltine flights is occurring or the two types have coexisted for many decades.

\section{Flights at Geneva, 1967-1981}

Figure 4 presents 5-year averages of moth catches from a single fixed location. Based on calendar date of peak catch and DD accumulations, trap catches during the periods of 1967-1971 and 1972-1976 exhibited typical bivoltine activity. Starting in 1977, increasing numbers of moths were captured in July, traditionally a month of limited activity. This increased midsummer activity occurs at DD accumulations of ca. 600 to 700 , which is similar to summations which occurred during peak flights at Paris, a univoltine location (Fig. 2B).

ECB flights not only differ in various parts of New York state, but also can shift at a given location. It is expected that shifts in flight patterns will continue to accur. In view of the changes which have occurred in flight trends in this state, it is important to monitor flights in numerous locations each season, particularly where susceptible processing crops are grown. Treatment decisions should be based on local flights, not generalized patterns.

\section{Acknowledgment}

We thank the processing companies who aided us in this study, the Vegetable IPM program at the NYSAES in Geneva, N.Y., for providing assistance in monitoring the flights, R. McMillen, who prepared the figures, and R. W. Straub, who aided us with the manuscript.

\section{REFERENCES CITED}

Apple, J. W. 1952. Corn borer development and control on canning corn in relation to temperature accumulation. J. Econ. Entomol. 45: 877-879.

Baskerville, G. L., and P. Emin. 1969. Rapid estimation of heat accumulation from maximum and minimum temperatures. Ecology 50: 514-517.

Caffrey, D. J., and L. H. Worthley. 1927. A progress report on the investigations of the European com borer. U.S. Dep. Agric. Bull. 1476. $155 \mathrm{pp}$ 

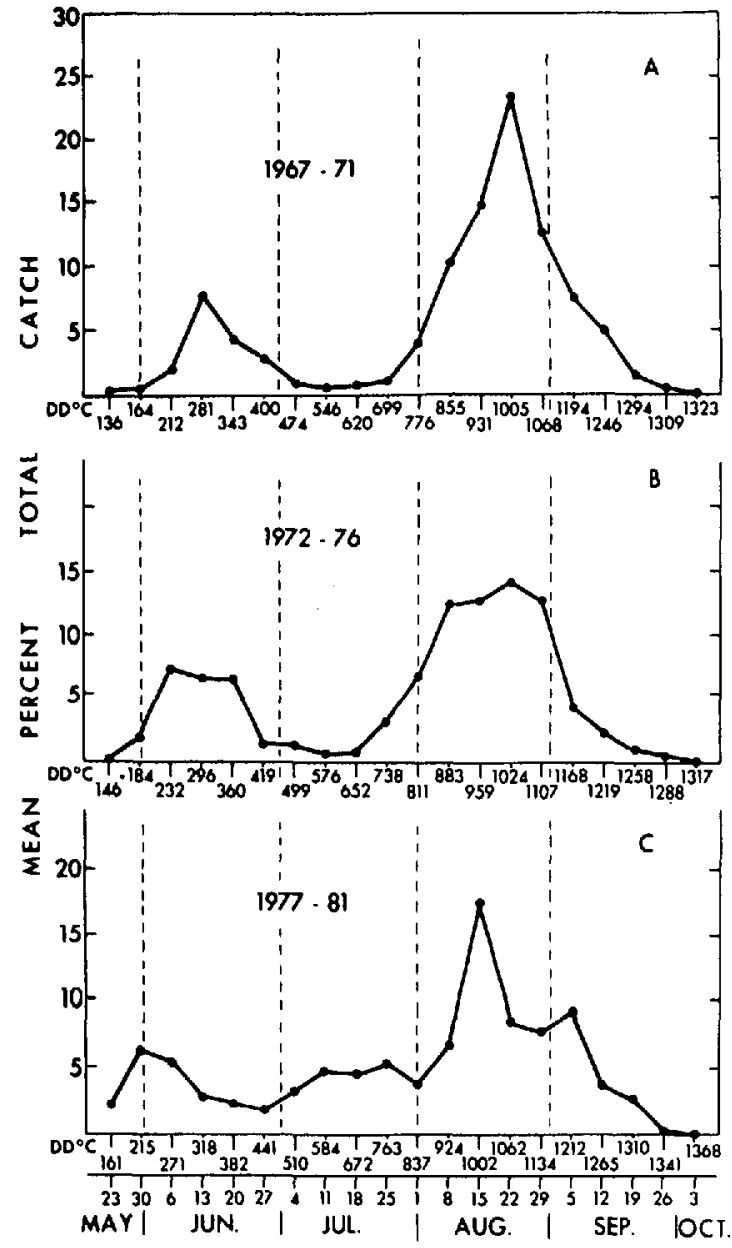

FrG. 4,-Moth flights near Geneva, N.Y., for 15 years. Trap catches and DD accumulations are averaged for 5-year periods.
Chiang, H. C. 1972. Dispersion of the European corn borer (Lepidoptera: Pyralidae) in Minnesota and South Dakota, 1945 to 1970. Environ. Entomol. 1: 157-161.

Chiang, H. C., J. L. Jarvis, C. C. Burkhardt, M. L. Fairchild, G. J. Weekman, and C. A. Triplehorn. 1961. Populations of European com borer, Ostrinia nubilalis ( $\mathrm{Hbn}$.) in field com, Zea mays L. Mo. Agric. Exp. Stn. Bull. 776. N.C. Reg. Pub. 129.95 pp.

Clement, S. L., W. L. Rubink, R. W. Rings, and M. A. Casey. 1981. Predicting flight activitics of the European corn borer. Ohio Rep. 66: 3-4.

Cress, D. and A. Wells. 1971. European corn borer...controlling it on: com, peppers, potatoes, snap beans. Mich. Ext. Bull E-584. 4 pp.

Dively, G. P., II, and J. E. McCully. 1979. Nature and distribution of European com borer feeding injury on snap beans. J. Econ. Entomol. 72: 152-154.

Linduska, J. J., and G. P. D. Dively. 1981. Foliar sprays to control corn earworms and European corn borers in snap beans, 1980. Insecticide Acaricide Tests 6: 51 .

McEwen, F. L., J. A. Adams, A. C. Davis, and H. B. Rinick, Jr. 1968. Corn borer in western New York. New York's Food Life Sci. Q. 1: 15-16.

McLeod, D. G. R. 1976. Geographical variation of diapause termination in the European com borer, Ostrinia nubilalis (Lepidoptera: Pyralidae), in southwestern Ontario. Can. Entomol. 108: 1403-1408.

McLeod, D. G. R., C. Ritchot, and T. Nagei. 1979. Occurrence of a two generation strain of the European corn borer, Ostrinia nubilalis (Lepidoptera: Pyralidae), in Quebec. Ibid. 111: 233-236.

Showers, W. B., G. L. Reed, and H. Oloumi-Sadeghi. 1974. Mating studies of female European corn borers: relationship between deposition of egg masses on corn and captures in light traps. J. Econ. Entomol. 67: 616-619.

Showers, W. B., H. C. Chiang, A. J. Keaster, R. E. Hill, G. L. Reed, A. N. Sparks, and G. L. Musick. 1975. Ecotypes of the European corn borer in North America. Environ. Entomol. 4: 753-760.

Wressell, H. B. 1953. Increase in a multivoltine strain of the European corn borer, Pyrausta nubilalis (Hbn.) in southwestern Ontario. 83rd Annu. Rep. Entomol. Soc. Ont. 83: $43-47$. 